\title{
ESPAÇO E EDUCAÇÃO \\ NA GEOGRAFIA CULTURAL
}

-ZENY ROSENDAHL'

\section{RESUMO}

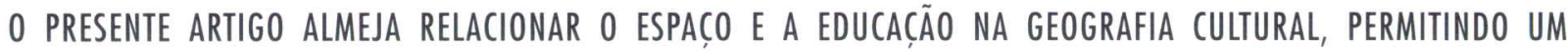
DEBATE SOBRE A DESIGUALDADE SOCIOEdUCACIONAL PRESENTE NA HISTÓRIA DA EDUCAÇÃO BRASILEIRA. PARA TAL, ABORDAREMOS $O$ ESPACSO NA PERSPECTIVA DA NOVA GEOGRAFIA CULTURAL, NA QUAL SERÁ RESSALTADA A ANÁLISE DA DIMENSÃO DO LUGAR, DA COMUNIDADE E DE SUA IDENTIDADE. EM SEGUIDA, TEREMOS UMA ANÁLISE CRÍTICA DAS DESIGUALDADES PEDAGÓGICAS DO PROJETO DE EDUCACÃO CATÓLICO DESTINADO AO SEXO FEMININO E INICIADO EM SÃO PAULO, NA CIDADE DE ITU, NA SEGUNDA METAdE dO SÉCULO XIX.

PALAVRAS-CHAVE: ESPAÇO, EdUCACÃO, gEOGRAFIA CULTURAL

Como pensar o espaço e a educação a partir da Geografia Cultural?

Como apresentar exemplos brasileiros que enriqueçam as reflexões desse Encontro Acadêmico?

As questões não são simples. Nesse texto abordaremos, primeiramente, o espaço na perspectiva da nova geografia cultural, na qual será ressaltada a análise da dimensão do lugar, da comunidade e de sua identidade. Na segunda parte, teremos uma análise crítica das desigualdades pedagógicas do projeto de educação católico destinado ao sexo feminino e iniciado em São Paulo, na cidade de Itu, na segunda metade do século XIX.

Nesse artigo consideramos, de um lado, a compreensão singular da experiência do lugar: lugares simbólicos criados pela ocupação humana do espaço e pelo uso dos símbolos para transformar aquele espaço em lugar (NORTON, 2000). De outro lado, consideramos, por intermédio de exemplo, a arte de educar, em sua singularidade ideológica, da ação católica conservadora do Brasil na década de 1850 .

\section{O Lugar na Análise Cultural Crítica}

No processo de renovação da geografia cultural, Mitchell (2000) lança em seu livro Cultural Geography: a critical introduction a construção de uma geografia cultural crítica, profundamente calcada no materialismo histórico e dialético. Nesse sentido, a geografia cultural é considerada pelo autor como sendo precisamente o estudo sobre o 
modo pelo qual as relações sociais particulares interceptam processos mais gerais. Um estudo centrado na produção e reprodução de lugares, espaços e escalas reais e as estruturas sociais que fornecem significados àqueles lugares, espaços e escalas. A geografia cultural deve ser mais do que estudo e análise. Em realidade, a geografia cultural renovada possui uma nítida natureza política e deve interagir ativamente nas políticas culturais no exercício do importante papel de preservar as diferenças culturais, em busca do estabelecimento da justiça cultural.

Ao refletir sobre a concepção da geografia cultural como sendo eminentemente política, a influência de Raymond Willians (2002) é fundamental para o estudo das práticas culturais distintas. O modelo teórico estudado pelo autor afirma que, em qualquer sociedade, em qualquer período particular, há um sistema central de práticas, significados e valores, o qual podemos corretamente chamar de dominante e eficaz. As desigualdades sociais manifestadas na sexualidade, no feminismo e nas relações entre economia e política são revigoradas após 1980 na ciência geográfica. Nesta interpretação, os geógrafos tentam refletir de modo mais geral sobre o conceito de lugar no sentido de pertencimento, na busca de esclarecer melhor a maneira como são construídas as identidades de lugares e as identidades de pessoas, como indivíduos e como membros de grupos sociais, levando em conta que há uma relação recíproca entre essas identidades (ROSENDAHL, 2005).

A preocupação atual dos geógrafos é, basicamente, os lugares como locais de conflitos políticos e simbólicos. Tuan (1980) define o lugar como uma unidade de espaço organizada mentalmente e materialmente para satisfazer as necessidades biossociais básicas, reais ou percebidas, de um povo e, além disso, suas aspirações estético-politicas superiores. Comungando com as ideias de Tuan (1980) e Norton (2000), a reflexão a respeito do conceito de lugar na Geografia Cultural inclui seis pontos: (i) sua criação é um ato social; os lugares diferem porque as pessoas os fizeram assim; (ii) são entidades autorreprodutivas; as pessoas aprendem e fornecem modelos alimentando determinadas crenças e atitudes; (iii) a cultura regional não existe separadamente das pessoas que a refazem enquanto a vivem; (iv) em uma economia capitalista mundial, lugares não são unidades autônomas, possuindo controle independentemente sobre o destino de seus residentes; (v) não são simplesmente os resultados não intencionais de processos econômicos, sociais e políticos; e, (vi) são locais potenciais fontes de conflito.

Lugar é um conceito-chave na Geografia, tendo merecido a atenção de diferentes pesquisadores segundo distintas perspectivas. Na presente análise, o lugar será considerado pela perspectiva da fé da religião católica apostólica romana. Ao explorar essa dimensão do lugar consideramos como a Instituição Religiosa delineia seus lugares religiosos e modifica-os para adaptá-los aos novos momentos conjunturais. O lugar religioso, entendido como reflexo de espaço vivido no cotidiano da fé, contribui para fortalecer as relações e os fluxos que se instauram pouco a pouco no espaço e que dão origem a uma identidade religiosa e a um sentimento de pertencimento ao grupo religioso envolvido. Essas posições teóricas 
nortearam a pesquisa em geografia cultural recente sobre a construção e a manutenção do lugar.

As relações da Igreja Católica com o território brasileiro estão na origem da divisão territorial do país figuradas nas dioceses (ROSENDAHL, 2003, 2005 e 2008). No Brasil os estudos empíricos ressaltam a estrutura espacial das unidades administrativas da Igreja no início da colonização portuguesa, 1551, com a primeira diocese até os dias de hoje. Na segunda parte deste texto, a diocese de São Paulo será o agente modelador do espaço, sendo representada na gestão religiosa por um bispo brasileiro, educador e detentor de fortes ligações políticas com Roma e o religioso de Chamberry (MANOEL, 2008). A geógrafa Rosendahl (2001, 2003 e 2005) afirma que os sucessivos rearranjos espaciais que a Igreja Católica Apostólica Romana constrói se modificam lentamente há vários séculos, com a finalidade de melhor corresponder à afirmação de seu poder. Tal poder pode corresponder a duas funções principais: uma de ordem religiosa e outra de ordem política. Há necessidade, em nível teórico, de explorar a experiência da fé no lugar em que ela ocorre. A localização do lugar simbólico religioso não é meramente descoberto, fundado ou construído. Ele é reivindicado, possuído e operado pela comunidade religiosa. Um dos instrumentos metodológicos utilizados para sua compreensão refere-se às relações de poder hierárquico de uma comunidade sobre a outra.

Na abordagem cultural em Geografia a vivência no lugar religioso se distingue por sua diversidade e coerência bastante significativas. A experiência religiosa é fundamental para os adeptos de diferentes tradições religiosas. Pesquisas realizadas em diferentes contextos históricos vêm identificando estratégias de poder no lugar. Manoel (2008) enfatiza o domínio das classes hegemônicas ao abordar o programa educacional e político, em escala mundial, destinado a combater a secularização do mundo moderno. Tal programa pedagógico destinou-se a promover a recatolicização os homens e a devolver-lhe a Igreja como o lugar central e fundamental na sociedade. O historiador Manoel (2008), em sua obra Igreja e Educação Feminina (1859-1911), auxilia os geógrafos no entendimento de como o lugar pode ser responsável pela permissão de que o projeto educacional católico seja implantado por longo tempo - aproximadamente um século até 1970 -, mantendo as mesmas características pedagógicas em sua difusão no Brasil. As alterações "novas" ao processo educacional datam da implantação da LDB 5692/71 no país e, com ela, da desativação de inúmeros colégios religiosos brasileiros diante das mudanças ocorridas.

Fé e educação são pontos centrais na leitura da dimensão do lugar, no paradigma da nova geografia cultural. O lugar escolhido em nossa análise é a cidade paulista de Itu, onde ocorreu a inauguração, em 1859, do primeiro colégio católico feminino. O Colégio Nossa Senhora do Patrocínio, sob a direção das freiras francesas da Congregação das Irmãs de São José de Chamberry, representa um exemplo de projeto de educação feminina em ligação mútua com a política, a oligarquia paulista e a religião. Alguns acontecimentos qualificam essa ligação no espaço e tempo estudados. Para melhor interpretar as desigualdades pedagógicas é necessário reconhecer o contexto político-social que as antecederam: 
(a) a Constituição Brasileira de 1891, que introduziu a laicização oficial no ensino público;

(b) o regime político republicano "não promoveu perseguição religiosa, não confiscou os bens eclesiásticos e negociou com a Igreja os próprios termos da Constituição" (MANOEL, 2008, p.19);

(c) o desenvolvimento da economia cafeeira permitiu condições para o desenvolvimento urbano;

(d) a formação da sociedade burguesa, com crescente valorização da cultura letrada, exigia do governo e da igreja ação na educação e na instrução;

(e) a fé religiosa era transmitida na rigidez da moral e no doutrinário católico;

(f) as novas concepções filosóficas do mundo e da vida estavam aliadas aos novos saberes científicos que caracterizavam as mudanças ocorridas no século XIX;

(g) essa nova concepção do mundo e da vida foi importante na formação das classes médias urbanas em ascensão progressiva no país (AZZI, 2004, p.317);

(h) "a educação escolarizada para mulheres não tinha sido uma preocupação da sociedade patriarcal brasileira" (MANOEL, 2008, p. 24);

(i) as escolas públicas existentes eram em número reduzido e não possuíam infraestrutura para atender os filhos e filhas da oligarquia e da classe média emergente

Diante desse cenário, a escola católica feminina representa uma pedagogia cultural associada ao fator econômico e geopolítico. Iniciada em 1859 , na região sudeste, perdurou até 1960 . Permaneceu até o Concílio Vaticano II indicar novos caminhos ao magistério católico. Na esfera da política educacional, apenas nos anos de 1970, com a implantação do projeto educacional LDB 5692/ 71 , as mudanças ocorreram no país.

Em harmonia com o tema - Espaço, Educação e Geografia Cultural - enfatizamos que a formação pedagógica feminina não pode ser estudada fora das contradições de classe existentes na Instituição Religiosa Católica. A compreensão pela Nova Geografia Cultural torna-se bastante simples quando consideramos o lugar dos acontecimentos históricos que precederam o evento. O geógrafo, ao propor uma abordagem crítica da dimensão espacial da cultura, prioriza os componentes materiais, sociais, intelectuais e simbólicos da cultura no lugar. O geógrafo considera em seus estudos os componentes do pensamento social e econômico interligados, pois representam coerência em sua estrutura principal no tempo e no espaço, isto é, a diversidade presente entre os diferentes representantes da sociedade estão impressos no lugar, no território, na paisagem, na região (CLAVAL, 1992).

Inicialmente devemos interpretar a localização da primeira escola de educação feminina no país e, em seguida, os agentes espaciais que deram origem a esse acontecimento. O lugar foi a cidade de Itu, no Estado de São Paulo. Na abordagem econômica, Itu qualifica-se como lugar de efervescência e riqueza oriunda do café. Os cafeicultores, desejosos de ampliação da área cultivada, procuravam avançar e instalar o progresso técnico-cientifico disponível, bem como 
difundir o produto econômico em escala internacional. Na dimensão política, o ideário paulistano manifestava-se favorável à Proclamação da República. Neste contexto é que "se manifestava a ambiguidade da oligarquia: desejava o moderno e temia a modernidade" (MANOEL, 2008, p.33). $\mathrm{Na}$ filosofia católica vigorava o ponto de vista tradicional. No Brasil "o curso histórico real parece ter atribuído sempre uma relevância muito grande à questão da unidade da Igreja Católica, unidade que somente estará assegurada na medida em que se acentue sua subordinação a Roma" (PAIM, 1984, p. 355). A unidade da doutrina conservadora consolidou um sistema educacional contraposto à escola pública leiga e gratuita, instituída pela política liberal.

\section{Desigualdade Pedagógica de Gênero: a Mulher}

\section{Enclausurada como Modelo de Virtude Cristã}

Nesta segunda parte do texto, abordaremos o comportamento da desigualdade social imposta às mulheres desde o início da sociedade colonial Riolando Azzi (2004) reporta que, segundo a tradição lusa, que sofrera grande influência da cultura islâmica, a mulher casada deveria ser mantida reclusa dentro das paredes do lar. Tal ideal luso foi transferido para a colônia como tantos outros comportamentos. A mulher enclausurada era apresentada como modelo de virtude cristã. No relacionamento sexual a ênfase recai na expressiva valorização da prática da virgindade. Em diferentes lugares, desde o século XVIII, foram criados conventos em várias localidades para receber as moças que renunciavam ao matrimônio por vontade própria, dos pais e/ou por não concordarem com tal comportamento. A leitura analítica católica de gênero e educação no Brasil, realizada por estudiosos nos três séculos de colonização, ressaltam o modelo denominado por Azzi de "sociedade sacral (...) dentro dessa concepção havia uma preocupação muito maior com os chamados direitos de Deus do que com os direitos humanos" (AZZI, 2004, p.312). As estratégias político-religiosas possuíam uma natureza oficial de poder da época. Acrescentamos que a fé católica constituía-se num forte instrumento de dominação sobre os aspectos culturais da sociedade. "A hierarquização celeste sacraliza também a ordem hierarquizada terrestre" (AZZI, 2004, p.316).

Foi na qualidade hierárquica e conservadora da Igreja católica que o primeiro colégio de educação feminina nasceu em Itu (SP). A Instituição Religiosa marca as diferenças de gênero e de classe social, desde os extratos mais ricos da oligarquia até as mais pobres meninas sem família. A desigualdade social imposta às mulheres no acesso diferenciado à educação foi a estratégia político-religiosa necessária para a classe dominante perpetuar seus valores próprios perante seus pares. O Colégio Nossa Senhora do Patrocínio pode ser interpretado como um local de reprodução social e, neste sentido, o lugar age como elemento estratégico sobre a sociedade. A desigualdade pedagógica significa não apenas um meio de perpetuar os privilégios da classe dominante, mas, também, um meio de controle e de reprodução da doutrina católica. O historiador Ivan Aparecido Manoel (2008) denomina de "teoria dos círculos concêntricos": da mãe cristã para filhos cristãos, de filhos cristãos para famílias cristãs, das famílias cristãs para a sociedade cristã. A estratégia 
fundamental da unidade da Igreja Católica perpetuava-se em escala local, regional e mundial.

Nas escolas das Irmãs de São José de Chamberry existiam três modalidades de ensino. As alunas poderiam cursar o internato pago, o externato gratuito e o orfanato. A diferença quantitativa de disciplina e o conteúdo programático estavam diretamente relacionados à posição hierárquica do grupo social ao qual as alunas pertenciam. A oligarquia no controle impunha às classes menos favorecidas a função de servir as classes imediatamente superiores. Isto pode ser comprovado pelo esquema elaborado Organização Pedagógica nos Colégios Femininos.

\section{Quadro 1: Organização Pedagógica nos Colégios Femininos}

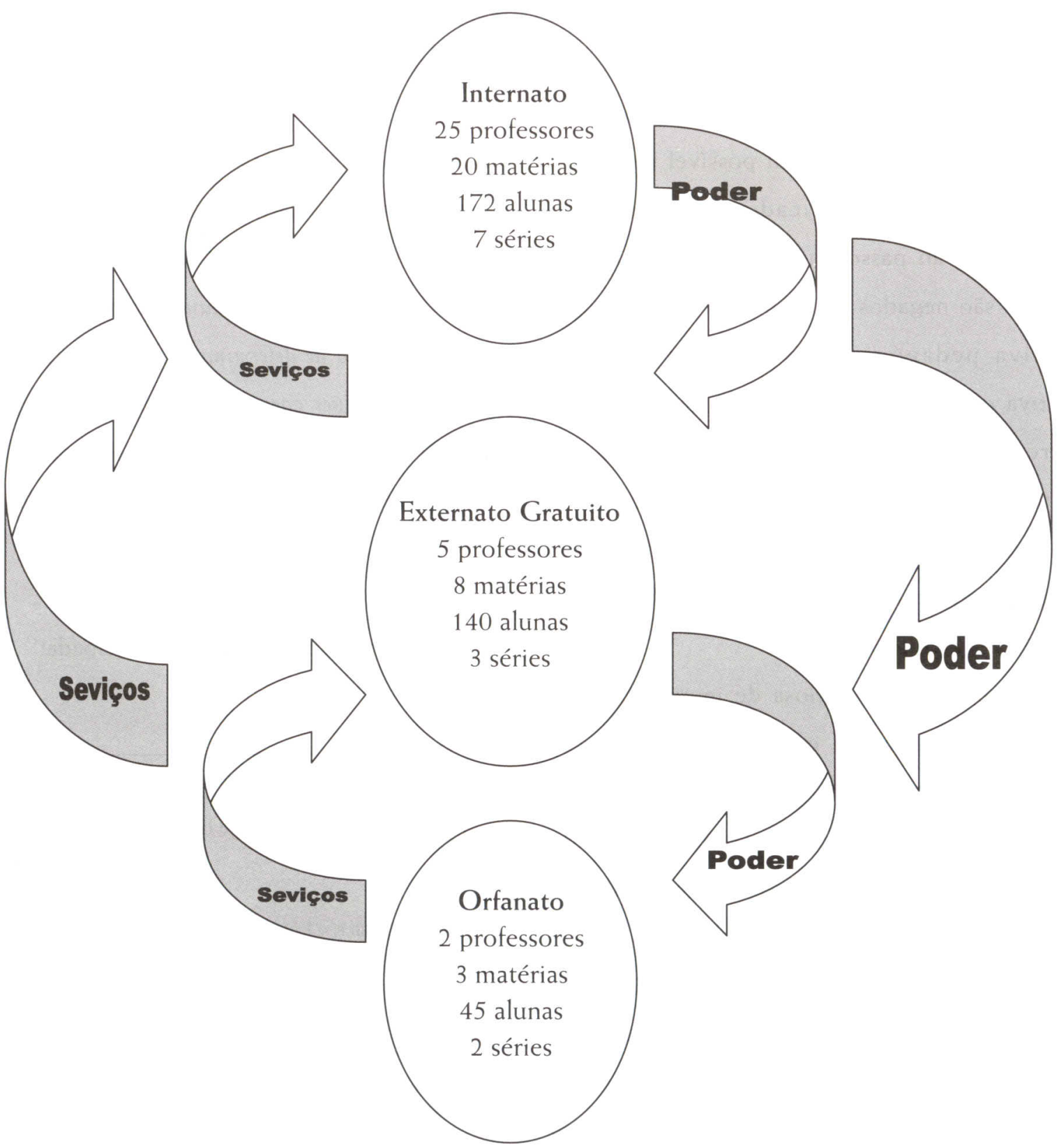

Fonte: Manoel (2008) I. A. "Igreja e Educação Feminina (1859-1919)" * Elaborado pela autora. 
Em nossa análise do esquema, o sistema educacional dominante é eficaz e central. Detém significados e valores que não são meramente abstratos, mas organizados e vividos. Sendo assim, a hegemonia não deve ser entendida no nível de mera opinião ou manipulação. Raymond Williams (2002) denomina que no verdadeiro nível da teoria da história de práticas, há um processo denominado de tradição seletiva, que, segundo os preceitos de uma cultura dominante eficaz, é sempre tratada como "a tradução", "o passado significativo". Acrescente-se que a seletividade é sempre o ponto central; o meio através do qual, de todo um possível passado e presente, certos significados e práticas são enfatizados, ao passo que outros significados e práticas são negados e excluídos. A organização seletiva pedagógica representa a tradição seletiva como comprova o leque de disciplinas oferecidas. As disciplinas eram gramática portuguesa, aritmética, geografia e cosmografia, história natural e botânica, noções de física, história sagrada e profana, caligrafia, literatura, francês e trabalhos manuais.

A ação político-religiosa de implantação da educação pedagógica em Itu teve êxito. Foi planejada por D. Antonio Joaquim de Melo, bispo da Diocese de São Paulo de 1851 a 1861, de nacionalidade brasileira, mais precisamente de Itu. Professor e religioso, planejou a criação de um colégio masculino em São Paulo sob a orientação dos padres jesuítas e a criação do colégio feminino dirigido por freiras francesas. A cidade de Itu representava uma centralidade de ideias liberais e republicanas em São Paulo. A relação entre família, Estado e Igreja permitiu, em Itu e também em outros locais, o controle católico sobre o sistema educacional. A questão de fazer e refazer a desigualdade social manifestada na sexualidade feminina e aplicada na educação representou um evento que perdurou por longo período. Iniciado em 1859 perdura até os dias de hoje.

\section{PARA NÃO CONCLUIR...}

No término desse texto, desejo acrescentar alguns temas para reflexões sobre espaço, educação e religião na tentativa de futuros estudos na geografia:

Como pensar educação, geografia e inclusão social em nossa sociedade?

Como reconbecer os agentes sociais formadores da desigualdade social manifestada na sexualidade dentro de determinado grupo étnico? Como conviver com o poder político impondo profissionais não especializados na gestão da arte de ensinar nas escalas municipal, estadual e federal?

Oxalá a justiça cultural seja antecipada!

NOTAS

Coordenadora do Núcleo de Estudos e Pesquisas sobre Espaço e Cultura - NEPEC. rosendahl@pesquisador.cnpq.br

\section{REFERÊNCIAS BIBLIOGRÁFICAS}

AZZI, R. A Teologia Católica na Formação da Sociedade Colonial Brasileira. Petrópolis: Vozes, 2004.

CLAVAL, P. La Culture Dans Tous les Espaces. Geograpbie et Cultures. Paris, n. 1, p. 85-111, 1992.

Ivan A. Manoel. Igreja e educação feminina (1859-1919). Uma face do conservadorismo. São Paulo: Ed. da Unesp, 1996.

MITCHELL, D. Cultural Geography: a critical introduction. Oxford: Blackwell Published, 2000

NORTON, W. Cultural Geography: themes, concepts, analyses. Oxford: Oxford University Press, 2000. 
PAIM, A. História das Ideias Filosóficas no Brasil. 3.ed. São Paulo: Convívio Fundação Nacional Pró-Memória, 1984

ROSENDAHL, Z. Espaço, Política e Religião. In CORREAA, R. L. (Orgs.). Religião, identidade e território. Rio de Janeiro: Bertrand Brasil, 2001

Espaço, Cultura e Religião: Dimensões de Análise. In: _ _ CORRÊA, R. L. (Orgs.). Introdução à Geografia Cultural. Rio de Janeiro: Bertrand Brasil, 2003.

Território e Territorialidade: Uma perspectiva Geográfica para o Estudo da Religião. In: CORRÊA
R. L. (Orgs.). Geografia: Temas sobre Cultura e Espaço. Rio de Janeiro: EdUERJ, 2005. p.191-226.

Os Caminhos da Construção Teórica: ratificando e exemplificando as relações entre espaço e religião. In: , CORRÊA, R. L. (Orgs.). Espaço e Cultura: Pluralidade

Temática. Rio de Janeiro: EdUERJ, 2008. p.47-78.

TUAN, Y.F. Topofilia. Tradução por Livia de Oliveira. São Paulo: Difel, 1980

WILLIAMS, R. Base e superestrutura na teoria cultural marxista REVISTA USP. São Paulo, n. 65 p. 210-224, mar./mai. 2005.

\section{ABSTRACT}

THIS ARTICLE AIMS TO RELATE THE SPACE AND EDUCATION IN CULTURAL GEOGRAPHY, ALLOWING A DISCUSSION OF SOCIAL AND EDUCATIONAL INEQUALITY IN THE HISTORY OF BRAZILIAN EDUCATION. TO DO THIS, FIRST, DISCUSS THE AREA IN PREPARATION FOR THE NEW CULTURAL GEOGRAPHY, WHICH IS EMPHASIZED IN THE ANALYSIS OF THE SIZE OF THE PLACE, THE COMMUNITY AND ITS IDENTITY. THEN WE HAVE A CRITICAL ANALYSIS OF EDUCATIONAL INEQUALITIES IN THE PROJECT OF CATHOLIC EDUCATION FOR tHE GIRLS AND STARTEd IN SÃO PAULO IN THE CITY OF ITU, IN THE SECOND HALF OF THE NINETEENTH CENTURY.

KEYWORDS: SPACE, EDUCATION, CULTURAL GEOGRAPHY. 